\title{
A atuação do serviço público na produção da paz
}

\author{
André Amorim Martins \\ Universidade do Estado de Minas Gerais (UEMG) \\ Cristina Silva Gontijo \\ Universidade do Estado de Minas Gerais (UEMG) \\ Daniella Almeida Silva Brum \\ Universidade do Estado de Minas Gerais (UEMG) \\ Cristina Alvarenga Santos \\ Universidade do Estado de Minas Gerais (UEMG)
}

Tânia Maria Alvarenga Alves

Universidade do Estado de Minas Gerais (UEMG)

\begin{abstract}
RESUMO
Este artigo tem como objetivo apresentar os resultados de pesquisa em que se buscou delinear os vários conceitos de paz, bem como verificar de que modo esses conceitos se apresentam em face dos responsáveis pelas secretarias municipais de uma cidade de médio porte. Os métodos utilizados foram a revisão sistemática de literatura e uma entrevista semiestruturada com os responsáveis pelas secretarias. Como resultado, concluiu-se que os trabalhadores conseguem descrever diversos conceitos de paz e investigou-se como esses conceitos são trabalhados por eles na prática do serviço enquanto atores públicos. Verificou-se, ainda, que a paz é utilizada como contemplação de um lugar em construção e compreendeu-se que sua produção não diz respeito à secretaria em que o trabalhador atua, gerando a inexistência de ações e a sua delegação para fora da alçada do servidor.
\end{abstract}

Palavras-chave: paz, estado, direitos humanos.

\begin{abstract}
The performance of the public service in the production of the peace

This article has as the objective to present the results of the research that searched to outline the various concepts of peace, as well as to check in which way these concepts present themselves in relation to the responsible people for the municipal secretaries of a city of medium tonnage. The methods utilized were the systematic revision and the semi-structured interview with the responsible people for the secretaries. We have found as a result, that the workers manage to get to describe various concepts of peace and how they are worked in the practice of the service as public actors. It was found that peace is used as a contemplation of a place in construction and that the production is not concerned to its Secretary, generating the inexistence of actions and its delegation outward of its work.
\end{abstract}

Keywords: peace, state, human rights.

Iniciamos, em 2010, o tema de pesquisa Produção da Paz, em virtude de um projeto existente naquela época, em um município de médio porte de Minas Gerais, intitulado Rede da Paz, que objetivava a aproximação e o trabalho dos poderes municipais (Executivo, Legislativo e Judiciário) para uma sociedade pacífica. Segundo dados do governo de Minas Gerais (2013), esse município faz parte do ranking estadual de cidades onde houve aumento no número de crimes violentos no ano de 2012 (Minas Gerais, 2013).

Ao constituirmos o grupo de pesquisa, iniciamos a discussão sobre qual seria o papel do Estado enquanto produtor de bens materiais e imateriais na nossa sociedade. O Estado seria capaz de produzir violência e também a paz? Nesse momento, fizemos a escolha de pesquisar a produção da paz por entendermos que as pesquisas sobre violência são constantes, enquanto os estudos sobre a paz ainda são incipientes. (Mocelim, 
Trindade, Souza \& Sperb, 2006).

Nossa primeira investigação encontrou em Foucault (1999) uma importante discussão sobre a evolução da função do Estado do período Estado da Espada para a Biopolítica. Sabemos que essa divisão é ainda pedagógica, por entendermos que o Estado ainda possui o direito constitucional de matar em casos excepcionais e o realiza de maneira indireta quando não produz de forma digna suas atividades para fazer as pessoas viverem.

O Estado da Espada corresponde historicamente ao período em que o soberano tinha como fonte de poder o exercício de matar aqueles que julgava ser anormais à sua política:

O súdito não é, de pleno direito, nem vivo nem morto. Ele é, do ponto de vista da vida e da morte, neutro, e é simplesmente por causa do soberano que o súdito tem direito de estar vivo ou tem direito, eventualmente, de estar morto. Em todo caso, a vida e a morte dos súditos só se tornam direitos pelo efeito da vontade soberana (Foucault, 1999, p. 286).

A partir do século XVIII, quando os indivíduos passaram a eleger o soberano ou a delegar o poder para ele, o direito de viver é colocado nesse contrato como algo fundamental. Com isso, "a vida dos homens, ou ainda, se vocês preferirem, ela se dirige não ao homem-corpo, mas ao homem vivo, ao homem ser vivo; no limite, se vocês quiserem, ao homem-espécie (...) que eu chamaria de uma 'biopolítica' da espécie humana." (Foucault, 1999, p. 289).

Essa mudança da razão do Estado, do campo do Direito para o da evolução humana, não tem mais a intenção de fazer o Estado crescer em riqueza e força, mas, sim, a de "limitar do interior o exercício do poder de governar" (Foucault, 2008, p.38). Caponi sintetiza isso dizendo que "o sujeito, enquanto sujeito de direitos, passou a ocupar um segundo plano em relação à preocupação política por maximizar o vigor e a saúde das populações" (Caponi, 2009, p.532).

O Estado produtor ocorre com a mudança da crença à razão (Ujvari, 2006), pois passa pela construção do Movimento Sanitário que pauta a organização da administração pública e de um Estado baseado em princípios de produção da pessoa. Para essa produção, o Estado começa sua tarefa de atravessamentos em fatores que proporcionam o desenvolvimento para o trabalho e para a preservação da integridade física das pessoas que irão construir o seu Estado.

Mudanças significativas ocorrem nesse período, como por exemplo, a visão sobre a produção humana segunda a qual todos estão aptos a ser produtores. A crença de que o homem é definido naturalmente sofre abalos e a construção da razão nesse homem proporciona um direcionamento para as oportunidades e para a liberdade de vender sua força de trabalho para quem "desejar".

Com o tempo, ferramentas sutis para produzir esse homem são construídas e aprimoradas. Temos aqui a oferta da educação continuada para aprimorar e aumentar a escolaridade; a construção da Previdência, para proporcionar mecanismos de proteção ao trabalhador; a construção de redes de saúde com estrutura física e administrativa organizada pela razão médica após o século XVIII; e a utilização de ferramentas de massificação da população com os estudos da epidemiologia e da demografia. Enfim, nesse modelo de produção, há a necessidade de fazer com que as pessoas vivam mais e que sua morte surja como o fim da existência e de todo o movimento produzido.

Hannah Arendt, discutindo a teoria do governo referente à vida, nos apresenta a expressão vita activa que designa as três atividades humanas fundamentais: labor, trabalho e ação.

As três atividades e suas respectivas condições têm íntima relação com as condições mais gerais da existência humana: o nascimento e a morte, a natalidade e a mortalidade. O labor assegura não apenas a sobrevivência do indivíduo, mas a vida da espécie. O trabalho e seu produto, o artefato humano, emprestam certa permanência e durabilidade à futilidade da vida mortal e ao caráter efêmero do tempo humano. A ação na medida em que se empenha em fundar e preservar corpos políticos, cria a condição para a lembrança, ou seja, para a história. (Arendt, 2007, pp. 16-17)

A perspectiva da vita activa traz a "tradição das experiências políticas da humanidade ocidental (...) o conflito entre o filósofo e a pólis (Arendt, 2007, p.20). A autora retoma à Aristóteles com seu bios politikos, e retoma Agostinho com sua vita negotiosa ou vita actuosa.

O emprego aristotélico remetia-se ao emprego do termo bios politikos nos assuntos meramente humanos (ocupação do belo consumindo os prazeres do corpo, vida dedicada aos assuntos da pólis e vida do filósofo). Para essa situação, somente a ação poderá estabelecer e manter um bios voltado para a condição humana autônoma. Essa forma de organização da vida denotava, por sua vez, um modo de organização social muito especial na cidade-estado. Forma que desapareceu ao longo dos tempos e que foi trabalhada posteriormente por Agostinho como engajamento ativo nas coisas do mundo e inquietude. Assim, a vita activa, a partir da ação passou a ser o único espaço para a vida política e a articular tudo 
que fosse necessário à vida e a ação pela contemplação (ou vita contemplativa) passou a ser o modo de vida livre, o modo de vida do filósofo ou concebida atualmente como o modo de atividade superior. (Arendt, 2007)

Contudo, Arendt (2007) defende que a vita activa deve prevalecer em todas as atividades dos homens, posto que, sem um único princípio global, nenhuma ordem pode ser estabelecida. Destaca que "tal premissa não é necessária nem axiomática" (p.26). Essa sua definição afirma que as ações políticas passem a ser mais voltadas para a vida das pessoas em vez de para a construção de grandes palavras ou pensamentos. Para nossa investigação, fica a proposição de que a paz perpétua deixe de ser um grande feito de uma pessoa só (ou organismo internacional, ou declaração internacional), mas que respeite a pluralidade dos homens e seja trabalhada por diversos sentidos das ações humanas. Deleuze (2002), faz uma crítica aos direitos humanos por entender que "essas declarações não são feitas pelas pessoas diretamente envolvidas". Essas leis não foram baseadas na vida atual ou em situações atuais. "Trata-se de criar, não de fazer aplicar os direitos humanos".

\section{O QUE É A PAZ?}

Na primeira etapa da pesquisa, em 2010 e 2011, realizamos uma revisão sistemática de literatura sobre o conceito de paz e encontramos uma convergência dos autores pesquisados para a relação da paz enquanto justiça e igualdade entre as pessoas. A Declaração Universal dos Direitos Humanos, de 1948, apresenta em seu escopo que é preciso "para o novo século, a equivalente complexidade de elaboração da relação entre o homem como sujeito de seu ser, isto é, a vivência da autonomia, e a definição da ordem jurídica, a ser experienciada não como prática de heteronomia, mas como construção de autonomias individuais, entrelaçadas e interdependentes" (Fishmann, 2001, p.68).

Galtung (ano como citado em Souza et al., 2006) afirma que a paz possui duas possibilidades: paz negativa como ausência de violência física direta, e paz positiva, quando há cooperação, justiça e solidariedade. $\mathrm{Na}$ busca de um conceito de paz que vá além de "ausência de algo", conforme apresentado por Guimarães (2003), encontramos diversos autores para os quais a paz está relacionada à resolução de conflitos (Maldonado, ano como citado em Souza, 2006; Sposito, 2001; D'Ambrosio, 2001).

O conceito apresentado por Fishmann é o mais próximo daquele que queremos trabalhar: a paz, não é um estado letárgico, ou a renúncia ao poder, mas a expressão mais viva e vigorosa do real poder, o que se articula como decisão e ato de vontade, de quem deseja construir (...) a capacidade de se indignar e de resistir contra injustiças. (Fishmann, 2001, p. 74)

\section{MÉTODO}

O presente trabalho teve por objetivo analisar como os trabalhadores das secretarias municipais e cidadãos de um município de médio porte em Minas Gerais lidaram com a questão da produção da paz no cotidiano da cidade para pautar a construção de políticas públicas voltadas para a discussão desse tema.

Foi adotada uma abordagem qualitativa por meio da qual se pretendeu analisar experiências significativas no âmbito da produção da paz. Foi selecionada uma amostra representativa das 5 secretaririas do Poder Executivo municipal que participaram da Rede da Paz: Saúde, Educação, Esportes, Cultura e Desenvolvimento Social. Em cada secretaria, propôs-se entrevista com quatro informantes-chave: o secretário da pasta, um coordenador, um profissional do quadro efetivo da secretaria e um cidadão. Teríamos, ao final, um total de 20 entrevistas realizadas.

$\mathrm{Na}$ fase de coleta de dados em campo, foram realizadas cinco das 20 entrevistas individuais, envolvendo quatro secretários e um coordenador. Houve grande dificuldade para encontrar os demais informantes-chave devido ao período eleitoral e à espera da indicação, pelos secretários, dos coordenadores e profissionais que estão diretamente relacionados com o tema. Essa adversidade já nos aponta um dado sobre a discussão desse tema dentro do governo municipal.

No estudo qualitativo, dois níveis de análise foram trabalhados. No primeiro, tem-se o campo das determinações fundamentais, que corresponde à construção do marco teórico para a análise (revisão sistemática de literatura através do banco de dados BVS-Psi). No segundo nível tem-se o campo empírico da investigação, ou seja, os discursos relativos à promoção da paz por parte dos sujeitos de pesquisa.

Em relação à amostra, é importante sublinhar que sua diversificação e o processo de saturação do discurso que ocorre durante o transcorrer das entrevistas são importantes critérios de validação da investigação (Minayo, 2010). Segundo a perspectiva adotada, diferentemente das técnicas tradicionais de entrevista, o pesquisador desenvolve com o entrevistado uma "conversação 'real", na qual pode responder a "questões 
perguntadas pelo respondente" e emitir "opiniões pessoais sobre as questões discutidas" (Fontana \& Frey, 1994, p. 371). Essa abordagem permite um espectro maior de respostas dos entrevistados e um conhecimento mais profundo de suas concepções. Para as entrevistas foram elaborados roteiros semiestruturados, contemplando os sujeitos de pesquisa definidos acima. $\mathrm{O}$ áudio de todas as entrevistas individuais foi gravado em voz para posterior transcrição e análise. Um Termo de Consentimento Livre e Esclarecido (TCLE) foi elaborado, no qual os sujeitos da pesquisa, após terem sido devidamente esclarecidos sobre a investigação, manifestaram a anuência a sua participação, conforme requerido pela Resolução n. 196/96 do Conselho Nacional de Saúde (CNS, 1996). Essa pesquisa foi aprovada pelo parecer 58/2010 no CEP da Funedi/UEMG. Contamos com o apoio da Fapeming - Papq $1 / 2012$.

O processo de análise obedeceu a três momentos, conforme sugere Minayo (2010). No primeiro, foram realizadas a ordenação e a classificação inicial dos dados, incluindo-se a transcrição das entrevistas, a "leitura flutuante" - caracterizada por ser uma primeira aproximação com os dados empíricos - e a estruturação do mapa das entrevistas. Nste, foram colocados, na vertical, os grupos de entrevistados organizados na forma de "corpus de comunicações", e na horizontal, os eixos analíticos definidos acima, em que as falas contidas em cada um dos corpi serão recortadas (Minayo, 2010). Para a constituição dos corpi, as entrevistas foram agrupadas em dois grupos: os gestores das secretarias e os coordenadores das secretarias. Como não obtivemos acesso aos profissionais e aos usuários, esses não entraram no mapa das entrevistas.

No segundo momento, mediante uma análise descritiva do material empírico, foi realizada a leitura detalhada do mapa de entrevistas, seja verticalmente, objetivando especificar os temas ou categorias empíricas centrais abordadas, dentro de cada um dos corpi ou grupo de entrevistados; seja horizontalmente, iniciando uma comparação entre as falas dos entrevistados em relação aos vários temas, organizados nos eixos analíticos definidos.

Por fim, no terceiro momento, concluiu-se o processo de análise, desenvolvendo-se a etapa interpretativa do processo de análise, na qual foi aprofundado o momento anterior, estabelecendo-se um confronto entre o discurso dos entrevistados e as reflexões teóricas em torno das categorias definidas acima.
Para que não ocorresse a identificação dos entrevistados, tratamo-loss como E1, E2, E3, E4 e E5. A numeração foi realizada de forma aleatória.

\section{RESULTADOS}

A análise das entrevistas nos proporcionou a construção das seguintes categorias: conceito de paz; a relação que as secretarias estabelecem com o conceito de paz; atitude da secretaria quando é acometida por algum agravo; ações do Estado para promover a paz; e, sociedade ideal dos entrevistados.

\section{Conceito de paz}

Identificamos inicialmente que os entrevistados possuem três conceitos de paz, que perpassam por:

"harmonia entre as pessoas" (E1, E3, E4);

"processo de construção através de ações humanas" (E2); e

"percepção de bem-estar psicológico e físico, além da ausência de violências e conflito ao redor" (E5).

\section{Relação que as secretarias estabelecem com o con- ceito de paz}

Ao tratarmos do trabalho desenvolvido por esses profissionais enquanto agentes públicos e executores de projetos relacionados ao tema da paz, nos deparamos com as seguintes respostas:

E1: "Não vejo relação direta de envolvimento da Secretaria com a paz na cidade". "Aqui dentro a gente não realiza ação específica sobre a paz"; "Não tem nenhum evento para promover essa paz, mas [isso] não tem que vir de fora, é de dentro das pessoas".

E2: "A ação mais visível é a gestão de um programa federal". "São as ações da proteção básica para o fortalecimento de vínculos familiares". "Proteção especial" e "política sobre drogas".

E3: "Todos os estabelecimentos, de alguma forma, trabalham a questão da paz". "Há pouco tempo tivemos um programa da Lei de Incentivo à Cultura que acontece dentro dos nossos estabelecimentos". "Temos projetos com o governo federal, projeto que há três anos é estruturador da rede".

E4: "Temos o projeto de revitalização dos espaços públicos. "Na periferia, temos Projeto Itinerante, Projeto Livre, Leve e Solto". "Oferta de eventos em espaços públicos". "Temos o projeto que trabalha com mil alunos da rede pública".

E5: "Se a gente for pensar, em essência, todas as ações que a gente tem aqui de promoção estão voltadas mesmo para a promoção da paz". "É fazer com que o cidadão, a pessoa, entenda que ela é a grande responsável pelas suas escolhas, no seu estilo de vida, na maneira com que ela age, na maneira com que ela se protege e conduz a sua vida". 


\section{Atitude da secretaria quando é acometida por algum agravo}

Indagamos dos entrevistados os procedimentos realizados por sua secretaria quando ocorre algum evento no qual é instaurado conflito e os profissionais necessitam registrar a situação

E1: "Chama a polícia e faz um Boletim de Ocorrência (BO)". "No Recursos Humanos, registra no Livro de Ata e, em alguns casos, leva para o Recursos Humanos da prefeitura". "Quando é servidor e usuário, é o BO mesmo".

E2: "Nós encaminhamos para o sistema de garantia de direitos, que é a Promotoria Pública e o próprio Judiciário, e trabalhamos no sentido de refazer vínculos com as pessoas".

E3: "Acionamos a família, o Conselho Tutelar e, se houver necessidade, também a polícia".

E4: "Não tive nenhuma situação desse tipo".

E5: "Eu diria que é muito incipiente, frágil na nossa rede, por vários motivos. Primeiro devido o ritmo sobrecarregado. Uma notificação sistematizada, tal como é proposta, toma um tempo muito grande. Outro fator é a questão da insegurança do profissional de querer estar envolvido nisso, como se fosse apresentar risco para ele, de ter retaliações, de ter depois algum tipo de revanchismo por parte de quem está sendo denunciado".

\section{Ações do Estado para promover a paz}

Questionados sobre as estratégias do Estado para promover a paz, os entrevistados responderam:

E1: "Eu nunca parei para pensar nisso. Não sei especificar para você quais seriam as estratégias que o Estado tem". "Mas não há muito o que ser feito pelo Estado". "As pessoas não têm essa cultura de paz dentro de si, não adianta vir com isso de fora, pronto. Não existe isso".

E2: "O sistema tem umas características muito democráticas, ele respeita as entidades que já estavam no território". "A educação também, a gente melhora as escolas, a própria saúde. Eu acho que a Constituição de 1988 tem belos caminhos para a paz no Brasil".

E3: "Eu sei que os estabelecimentos estaduais estão na mesma luta. Cada estabelecimento procura buscar infinitas atividades que façam a criança se solidarizar, se ver no outro, mas assim... Uma ação que tenha a chancela do Estado... A não ser essa que já aconteceu em algumas regionais e vai acontecer na nossa regional".

E4: "Eu não saberia responder sobre o que o Estado faz, e na verdade, o entendimento que eu tenho é que a gente tem que deixar de delegar ao Estado o papel de ser educador".

E5: "Seguramente tem a questão do desenvolvimento social, da educação e da saúde. Acho que são esses três pilares que são os principais."

\section{Sociedade ideal dos entrevistados.}

No final da entrevista, indagamos dos sujeitos-chave a sociedade ideal que eles imaginam.
E1: "Eu acho que o ideal seria a gente conseguir resolver nossos problemas dentro da nossa família, com conversa, com entendimento, com mais diálogos". "O ideal seria que as pessoas conseguissem se controlar". "As pessoas têm que ter essa paz dentro de si".

E2: "Sociedade ideal é aquela que os conflitos possam ser vividos, sem necessariamente uma violência descabida. Não sei se é possível, não acho também que essa coisa é viável. Acho que sempre teremos violência mesmo, mas a utopia dos Direitos Humanos que eu acho que é a utopia da paz ela é interessante como parâmetro de discussão, mas a sociedade ideal talvez seja a que as pessoas vivam em paz, mas acredito que ela seria muito chata".

E3: "A sociedade ideal é aquele estado de harmonia, cooperação, solidariedade".

E4: "Uma cidade em que a gente convivesse, transitasse sem tensão e sem preocupação".

E5: "Eu vejo que isso é um trabalho, que por ser uma questão cultural, envolve um número muito grande de pessoas da própria sociedade. É uma coisa conjunta mesmo, quase um batalhão que é necessário para que a gente possa dizer que está influenciando nos rumos disso."

\section{DISCUSSÃO}

O discurso dos entrevistados sobre a paz corrobora o encontrado na literatura sobre paz positiva e negativa. Temos a paz positiva enquanto um processo humano, um estado de contemplação do pensamento que leva as pessoas a lidarem "pela cooperação e pela coexistência harmônica". A paz negativa "é definida como ausência de guerra ou de violência" (Souza, Sperb, 2006, p. 219).

O conceito de paz proposto pelos Direitos Humanos e por Fischmann (2001), como campo de embate, não aparece no discurso dos nossos entrevistados, isto é, essa instituição chamada $p a z$ está em permanente tensão, assim como a sociedade em que vivemos. Para início da nossa discussão, é importante salientar que, na esfera das políticas, a composição as máquinas de guerra (forças objetivas e subjetivas) são ferramentas de embate e tensionamento das formas de vida. Não há como as pessoas ficarem de fora deste território ou isoladas das decisões. As dimensões institucionais (Baremblitt, 2002) familiares, judiciais, linguagem, educação, divisão do trabalho, etc. são espaços de disputa dentro desse cenário. Por isso, não há como renunciar ao poder, expressar suas vontades e ser isolado. Estamos todos atravessados e constituindo-nos por esse estado de transformação.

É importante destacar que as formas de atuação constituem o papel político do agente público. Mesmo com uma tentativa de neutralidade - como podemos 
verificar no discurso de E1 -, que, na existência de conflito, chama a polícia ou transfere a decisão para outro departamento, ali estão instaurados uma decisão e um ato de vontade. A premissa de que a produção de paz não diz respeito à sua secretaria do entrevistado é uma posição definida. Isso gera exatamente a inexistência de ações e a delegação para fora de seu escopo. Não nos parece ingenuidade chamar a polícia para as pessoas "que não têm a cultura de paz dentro de si".

Essa postura apresentada, converge com as tendências do Estado da Espada, de "deixar as pessoas viverem" (Foucault, 1999, p286) sem ter a visão de produzir algo com elas. É uma tendência de que a despreocupação ou omissão do Estado com as formas de existência não o fazem atuar ativamente como um Estado que se preocupa com a integridade das pessoas e produz algo com elas.

$\mathrm{O}$ que foi apresentado pelas secretarias pesquisadas é a ausência de ações para lidar diretamente com o tema da produção da paz. Como apresentado por E5, esse tema apareceu aqui como "essência" das políticas que já se produzem, mas não foi apresentado um projeto que tenha no seu objetivo a produção da paz. Realizamse diversos projetos que, em sua maioria, são encaminhamentos da esfera federal e que têm como resposta terciária ou quaternária a produção da paz, mas sem meios de mensurar o nível de paz que esses projetos produziram devido à "ausência de guerra ou violência" ou "não parar para pensar sobre isso" (E1).

Reflexo da questão acima, parte dos entrevistados não soube dizer como se dá a atuação do Estado para promover a paz. Outra parte pontuou novamente que é na essência dos estabelecimentos e das ações do Estado que se encontra a presença da paz. Com essas respostas os entrevistados dão a entender que, mesmo sendo secretários e coordenador, não se posicionam enquanto representantes do Estado . Não se sentem autorizados a falar enquanto produtores de ações voltadas para o público. Optam por encaminhar os problemas para outros lugares em vez de resolvê-los no local de origem. O Estado é de fora: fora de mim, fora do meu território, fora da minha cidade. Certamente, é por isso os gestores e cidadãos delegam para o Ministério Público, Polícia e Conselho Tutelar a indignação com as mazelas sociais que têm reflexo nos estabelecimentos públicos que gerenciam.

A democracia e suas formas de materialização forjadas no Estado brasileiro (lembradas por E5 como desenvolvimento social, educação e saúde) foram trabalhadas pelos entrevistados como formas de produção da paz, enquanto contemplação de um lugar em construção e de um território que se faz presente independentemente da cidade, ou seja, uma contemplação que foge do espaço da ação humana proposta por Arendt (2001) no qual "todo movimento, os movimentos do corpo e da alma, bem como o discurso e o raciocínio, devem cessar diante da verdade" (p.23).. Logo, como estipulado pelas Secretarias, a ação fica subjugada à contemplação, ocasionando novamente a ausência de políticas produzidas para efetivação da paz no município.

\section{CONSIDERAÇÕES FINAIS}

Por se tratar de uma pesquisa com objeto pouco explorado na Psicologia brasileira, consideramos que os resultados foram positivos, apesar do viés que tivemos no percurso - a pesquisa foi realizada durante o período eleitoral, o que fez com que os informantes-chave da pesquisa estivessem pouco acessíveis. O resultado disso foi não termos entrevistado todos os informantes preconizados inicialmente.

Nosso questionamento de análise da produção da paz no cotidiano da cidade por meio do trabalho dos servidores municipais (quatro secretários e um coordenador) nos mostrou certo desconhecimento dessa questão por parte dos responsáveis pela construção e manutenção do bem público.

Ficamos surpresos com estratégias de opressão utilizadas para sanar conflitos dentro do serviço e com o posicionamento de que as ações de produção da paz se dão fora dos estabelecimentos que gerenciados. Inclusive, deixou-se transparecer que, dentro da organização do governo, não ocorrem processos democráticos, pois as posturas dos entrevistados enquanto atores públicos não são efetivadas em sua plenitude e há poucos espaços para exercer plenamente a produção da paz e/ou a democracia.

Para Bobbio, a premissa do poder democrático é "a existencia e a persistencia das liberdades fundamentais" (Bobbio, 2011, p 33).

É preciso que aqueles que são chamados a decidir ou a eleger os que deverão decidir sejam colocados diante de alternativas reais e postos em condições de poder escolher entre uma e outra. Para que se realize esta condição é necessário que aos chamados a decidir sejam garantidos os assim denominados direitos de liberdade, de opinião, de expressão das próprias opiniões, de reunião, de associação, etc. (Bobbio, 2011, p.32)

Com essa definição, podemos indagar: como os ci- 
dadãos manifestam seu poder e direitos? Afinal, Estado democrático não é apenas fornecedor de educação, saúde e assistencia social, como manifestado pelos secretários. Será preciso construir outras formas de contemplação a partir das tensões propostas pelos direitos humanos e ações que sejam baseadas na realidade das pessoas que sofrem com a violência produzida pelo Estado a partir de seus representantes nas seceratarias municipais.

\section{REFERÊNCIAS}

Arendt, H. (2007). A Condição Humana. 10ed. Rio de Janeiro. Forense Universitária.

Baremblitt, G. (2002). Compendio de Análise Institucional e outras correntes: teoria e prática. 5ed. Belo Horizonte. Instituto Felix Guattari.

Bobbio, N. (2011). O futuro da democracia. 12ed. São Paulo. Editora Paz e Terra.

Caponi, S. (2009). Biopolítica e medicalização dos anormais. Physis. p.529-48.

D’ambrosio, U. (2001). "Paz, educação matemática e etnomatemática". Teoria e Prática da Educação, Maringá, PR, v. 4, n. 8, p.15-33, Jun. 2001. Disponível em: $<$ http://www.ufpa.br/npadc/gemaz/textos/artigoss $/$ paz $\% 20$ educacao $\% 20 \mathrm{e} \% 20$ etnomatematica(ARTIGO).pdf > Acesso em: 10/04/2012

Deleuze, G. O abecedário de Gilles Deleuze. Entrevista com G.Deleuze. Editoração: Brasil, Ministério da Educação, TV Escola, 2001. Paris: Éditions Montparnasse, 1997, VHS, 459min DELEUZE, G. Espinosa: filosofia prática. Ed. Escuta. São Paulo, 2002.

Deleuze, G. Guattari, F. (2006) Rizoma. In: Deleuze, G. Guattari, F. Mil Platôs: capitalismo e esquizofrenia. São Paulo, Editora 34

Fischmann, R. (2001). "Educação, direitos humanos, tolerância e paz". Paidéia, v. 11, n. 20, p. 67-77, 2001. Disponível em: < http://www.scielo.br/pdf/paideia/v11n20/08.pdf $>$ Acesso em: 17/04/2012

Fontana, A; Frey, J.H. (1994). Interviewing: the art of science. In: Denzin N \& Lincoln Y (eds). Handbook of qualitative research. (pp. 361-376). London, Sage

Foucault, M. (1999). Aula de 17 de março de 1976. In: Foucalt, Michel. Em defesa da sociedade. Tradução: Maria Ermantina Galvão (pp.285-316). São Paulo: Martins Fontes.

Foucault, M. (2006). Nascimento da Clínica. 6Ed. Rio de Janeiro: Forense-Universitária.
Foucault, M. (2008). Nascimento da Biopolítica. São Paulo. Martins Fontes.

Lane, S. T. M. (2007). A Psicologia Social e uma nova concepção de homem para a Psicologia. In S. T. M. Lane \& W. Codo (Eds.), Psicologia Social: O homem em movimento (pp. 10-19). $2^{\mathrm{a}}$ ed. São Paulo, SP: Brasiliense.

Souza, L.K.; Sperb, T.M. (2006). "Assimetria entre paz, guerra e violência na concepção de crianças e adolescentes". Psico-USF, v. 11, n. 2, p. 219-227, Jul./Dez. Disponível

$<$ http://www.scielo.br/pdf/pusf/v11n2/v11n2a10.pdf> Acesso em: 10/04/2012

Romesín, H.M.; Yáñez, X.P.D. (2004). "Ética e Desenvolvimento Sustentável - Caminhos para a Construção de uma Nova Sociedade". Psicologia \& Sociedade, Porto Alegre, v. 16, n. 2, p. 102-110, Set/Dez. Disponível em: $<$ http://www.scielo.br/scielo.php?script=sci_arttext\&pid=S0102-

$71822004000300013 \& \operatorname{lng}=$ pt\&nrm $=$ iso $>$ Acesso em $17 / 04 / 2012$

Minas Gerais (2013). Informativo dos Índices de Criminalidade de Minas Gerais. 2012. Disponível em https://www.seds.mg.gov.br/images/seds_docs/Seds/informativo $\% 20 \mathrm{indices} \% 20 \mathrm{mg} \% 202012$.pdf . Acessado em 25 de janeiro de 2013.

Minayo, M.C.S (2010). O desafio do conhecimento: pesquisa qualitativa em saúde. 12ed. São Paulo. Hucitec

Souza, L.K.; Mocelim, L.P.; Trindade, F.B.; Sperb, T.M. (2006). "Psicologia e paz: a perspectiva de estudantes universitários". Arquivos Brasileiros de Psicologia, v. 58, n. 1, p. 12-20. Disponível em: <http://pepsic.bvsalud.org/pdf/arbp/v58n1/v58n1a03.pdf $>$ Acesso em: 10/04/2012

Souza, L.K.; Mocelim, L.P.; Trindade, F.B.; Sperb, T.M. (2006). "Psicologia e paz: a perspectiva de estudantes universitários". Arquivos Brasileiros de Psicologia, v. 58, n. 1, p. 12-20. Disponível em: <http://pepsic.bvsalud.org/pdf/arbp/v58n1/v58n1a03.pdf > Acesso em: $10 / 04 / 2012$

Ujvari, S.C. (2006). História e suas epidemias: a convivência do homem com os micro-organismos

Recebido em: 27/06/2013 Primeira decisão editorial em: 11/02/2015 Aceito em: 17/03/2016 